\title{
Analysis of Residual Stresses in Hot-rolled H-shapes*
}

\section{By Takashi KUSAKABE** and Yutaka MIHARA***}

\section{Synopsis}

The generating mechanism of residual stresses in hot-rolled $H$-shapes is studied to estimate the magnitude of residual stresses through numerical methods and a method for computing the internal stresses from the temperature distribution throughout the cooling process. The following results are obtained:

(1) The magnitude and the distribution of residual stresses are estimated through simplified two dimensional models using the finite difference methods. The computed distributions of temperature during cooling and the residual stresses agree well with the experimental results.

(2) The principal cause for the formation of residual stresses is the large temperature difference between the flanges and the web during cooling. The maximum amount of difference $\left(T_{1}-T_{3}\right)$ max. between the temperature at the flange-center and the web-center during cooling is the main factor in deciding the magnitude of residual stresses.

(3) Shape geometry has a large effect on the magnitude of residual stresses. When the shape is geometrically similar, the larger shape has larger residual stresses. When the width and height is the same, the $H$-shapes with smaller $t_{1} / t_{2}$ has larger residual stresses. $t_{1} / t_{2}$ is the ratio of thickness of web $\left(t_{1}\right)$ and flange $\left(t_{2}\right)$.

(4) The effects of initial temperature difference $\left(T_{1}-T_{3}\right)$ on the residual stresses is very large. When the initial temperature difference is large, the residual stresses become large. On the other hand, the height of initial temperature has little effect on residual stresses when the temperature difference is the same.

\section{Introduction}

In recent years, outstanding developments have been made in Civil Engineering and Architecture as is evidenced by the increasing number of large structures, such as multi-storied buildings and elevated highways. From the very nature of their functions, the columns and beams used in these large structures must necessarily be made of light weight members possessing a high section modulus, so that there is an increasing demand for large $\mathrm{H}$-shapes which satisfy these requirements. However, although productivity for $\mathrm{H}$-shapes manufactured by hot rolling is high, they are under the disadvantage of being difficult to handle due to the presence of tensile residual stresses in the flanges and compressive residual stress in the web. In general, $\mathrm{H}$-shapes possessing excellent sectional functions such as large $\mathrm{H}$-shapes with high webs and small $t_{1} / t_{2}$ ratios (web thickness/flange thickness) have a large residual stresses which give rise to the following problems.

1) Warping when subjected to cutting work

2) Deterioration of their resistance to buckling and of their bending performance when used as members for beams and columns

\section{3) Cracking during flame cutting}

However, up to the present, only 2 or 3 publications on residual stresses in $\mathrm{H}$-shapes are available. ${ }^{1-3}$ ) For this reason, the authors conducted a series of researches on the subjects related to residual stresses developed in $\mathrm{H}$-shapes and this is a report regarding the analysis of the generating mechanism of residual stresses in H-shapes in order to grasp the actual conditions of the residual stresses generated in $\mathrm{H}$-shapes, and simultaneously, to develop the methods of predicting the magnitude of residual stresses through calculations. Also, a separate report ${ }^{4)}$ will be submitted on (1) prevention and reduction of the generation of residual stresses and (2) problems caused by residual stresses.

\section{Generating Mechanism of Residual Stresses}

Ordinarily, the manufacturing processes of rolled H-shapes is as follows: beam blanks produced on blooming and roughing mills are hot rolled on universal and edging mills to be shaped and are then placed on a cooling bed where they are cooled into the final product. In these manufacturing processes, the following items are thought to be the cause of residual stresses:

1) Non-uniform plastic deformations between web and flanges in hot rolling.

2) Nonuniformity in the temperature between the web and flanges originated during the rolling and cooling process.

However, the material is being rolled at high temperatures of between $1000^{\circ} \sim 1200^{\circ} \mathrm{C}$, and has a low flow stress, so that it is not possible to form such a high stress as $20 \mathrm{~kg} / \mathrm{mm}^{2}$, as is present in residual stress, during rolling. In addition, the temperatures after rolling are about $700^{\circ} \mathrm{C}$ for the web and $900^{\circ} \mathrm{C}$ for the flanges which are sufficiently high enough to allow re-crystallization, and are also high enough to allow stress-relief. Consequently, it cannot be thought that first item is the cause of the generation of the residual stresses, but that second item is the principal cause.

For this reason, the causes which may originate uneven temperature distribution during cooling after the end of rolling were studied. The object of the paper is to discuss the effects of temperature distribution on residual stresses and the method of estimating the magnitude of the residual stresses.

* Originally published in Tetsu-to-Hagané, 65 (1979), 1375, in Japanese. English version received July 16, 1979.

** Nippon Kokan K.K., Marunouchi, Chiyoda-ku, Tokyo 100.

*** Technical Research Center, Nippon Kokan K.K., Minamiwatarida-cho, Kawasaki-ku, Kawasaki 210. 


\section{Method for Calculating Residual Stresses}

\section{Temperature Analysis}

As previously mentioned, the major cause of the formation of residual stresses in rolled $\mathrm{H}$-shapes is the non-uniform distribution of temperatures through the cross section during cooling. Therefore, in order to calculate the residual stress of hot-rolled members, it will be necessary to investigate the progression of the material through the various stages of temperature and stress from the time immediately after completion of the rolling operation to the time it is cooled to room temperature. It is impossible to obtain temperature-time solution analytically under complicated boundary conditions and variable coefficients. Consequently, the numerical method based on finite-difference method was used to obtain the temperaturetime solution.

\section{The Equation for Thermal Conductivity and Solution}

A study of the heat flow in and out of a small cubic element within a material, has led to the following three-dimensional thermal conductivity equation: ${ }^{4)}$

$$
\frac{\partial}{\partial x}\left(\lambda \frac{\partial T}{\partial x}\right)+\frac{\partial}{\partial y}\left(\lambda \frac{\partial T}{\partial y}\right)+\frac{\partial}{\partial z}\left(\lambda \frac{\partial T}{\partial z}\right)+Q=\rho C_{p} \frac{\partial T}{\partial t}
$$

This expression is generally known as the Fourier's formula and is valid for the interior of the material. On the other hand, for the conditions of the boundaries on the surface of a material, the following equation can be established:

$$
-\lambda \frac{\partial T}{\partial n}=H \cdot\left(T-T_{a t m}\right)
$$

This equation is often referred to as Newton's law of cooling.

Although Eqs. (1) and (2) cannot be solved analytically, a numerical solution can be obtained with comparative ease by making the following assumptions.

(1) To be handled as a two-dimensional problem by assuming that there is no heat flow in the axial direction.

(2) The boundary conditions and the initial temperature distribution are already known.

(3) The boundary conditions are symmetrical as regard to the 2 axes of symmetry of the material.

(4) The material is an isotropic body and its physical coefficients are known as a function of temperature.

(5) There is no heat source within the material, and the coefficient of heat transfer is known.

Through the five assumptions as given above, Eq. (1) can be rewritten as Eq. (3) as follows:

$$
\frac{\partial}{\partial x}\left(\lambda \frac{\partial T}{\partial x}\right)+\frac{\partial}{\partial y}\left(\lambda \frac{\partial T}{\partial y}\right)=\rho C_{p} \frac{\partial T}{\partial t}
$$

In addition,

(6) If it is further assumed that $\lambda$ is only slightly related to position, then,

$$
\begin{aligned}
& \partial \lambda / \partial x \cong 0, \quad \partial \lambda / \partial y \cong 0 \\
& \lambda\left(\partial^{2} T / \partial x^{2}\right)+\lambda\left(\partial^{2} T / \partial y^{2}\right)=\rho C_{p} \partial T / \partial t
\end{aligned}
$$

In order to obtain a numerical solution through Eqs. (2) and (4), a cross-section was divided into mesh form and the calculus of finite difference was used to solve the problem. Generally, when solving non-steady-state equations of this type through finite difference, the temperature $T_{i, j, k+1}$ at points $(i, j)$ after lapse of time $(k+1) \times \Delta t$ through the known temperatures at 5 points, vis. $T_{i-1, j, k}, T_{i, j, k}, T_{i+1, j, k}$, $\mathcal{T}_{i, j-1, k}$ and $\mathcal{T}_{i, j+1, k}(i, j$ and $k$ are the positive integers) at $k \times \Delta t$ time. However, in this method for stabilizing the solution, limitation is placed on the time interval, $\Delta t$ by Eq. (5).

$$
\Delta t \leqq \frac{1}{2 \lambda / \rho C_{p} \cdot\left(1 / \Delta x^{2}+1 / \Delta y^{2}\right)}
$$

Now, with regard to carbon steel, $\lambda / \rho \cdot C_{p}$ is about 270 $\left(\mathrm{cm}^{2} / \mathrm{hr}\right)$, and if $\Delta x, \Delta y$ are equal to $1.5 \mathrm{~mm}$, Eq. (5) gives the condition of $\Delta t \leqq 0.1 \mathrm{sec}$. So to simulate a cooling period of $1 \mathrm{~min}$, it requires at least 600 repetitions of calculations, and to simulate for $1 \mathrm{hr}$, it requires over 3600 calculations. For this reason, if small values are allotted for spacing, the computations to be made will be exceedingly numerous even if high speed computers are used. When actual calculations were carried out to simulate a cooling period of $1 \mathrm{hr}$ through the Explicit method, it required from about $30 \mathrm{~min}$ to $1 \mathrm{hr}$ to complete the process. For this reason, a special finite difference method called the Implicit Alternating Difference (IAD Method) was adopted to carry out the computations. ${ }^{7}$ In this method, to find out the temperature after lapse of time $(k+1) \times \Delta t$, an equation is established between 3 unknown temperatures, such as $T_{i, j, k+1}, T_{i-1, j, k+1}$, $T_{i+\mathbf{1}, j, k+1}$ and 3 known temperatures $T_{i, j, k}, T_{i, j-1, k}$, $\mathcal{T}_{i, j+1, k}$. In the coefficient matrix of this equation system, as all the elements are zero with the exception of the diagonal matrix and its upper and lower values, solutions are obtained with comparative ease. A feature of this method lies in the fact that stable solutions can be obtained regardless of the size of the mesh spacing $(\Delta x, \Delta y)$ or the length of the time division. Therefore, longer time intervals can be chosen as compared with the Explicit method, and solutions are obtained with a comparatively small number of repetitive calculations. We were able to carry out calculations, simulating $1 \mathrm{hr}$ of cooling time, including stress calculations, in about $3.6 \mathrm{~min}$. The number of mesh points was 185 . The 3 temperatures in the $x$ direction, $T_{i, j, k+1}, T_{i-\mathbf{1}, j, k+1}$, and $T_{i+1, j, k+1}$ were first used as the unknown temperatures in the calculations and, in the next time step, the 3 temperatures in the $y$ direction, $T_{i, j, k+2}, \quad T_{i, j-1, k+2}$, and $T_{i, j+1, k+2}$ were used as the unknown temperatures. The temperatures in the two directions were used alternately as the unknown temperatures.

\section{Thermo-physical Coefficient}

The thermal coefficient $\left(\lambda, C_{p}, H\right)$ included in Eqs. (1) to (5) are dependent on temperature. Figures 1 to 3 show the variation of each coefficient for carbon steel (about $0.2 \% \mathrm{C}$ ) with temperature. ${ }^{8}$ ) Although convection and radiation will affect the coefficient of 
heat transfer on the surface of the material, mutual radiant heat is obstructed on the inner surface of the web and flange. For this reason, in making the calculations, the coefficient of heat transfer on the inner surface of the web and flange was estimated through the reduction factor due to the shape. The value for the physical coefficient changes from the time step $k$ to $k+1$. The average value is used for the calculation of temperature at the time of step $k+1$. However, temperature $T_{k+1}$ is not known at the time when the temperature for $T_{k+1}$ is to be computed. Accordingly, first, the temperature at time $T_{k+1}$ is extrapolated through a straight line from the temperatures at times $T_{k-1}$ and $T_{k}$, and the physical constant

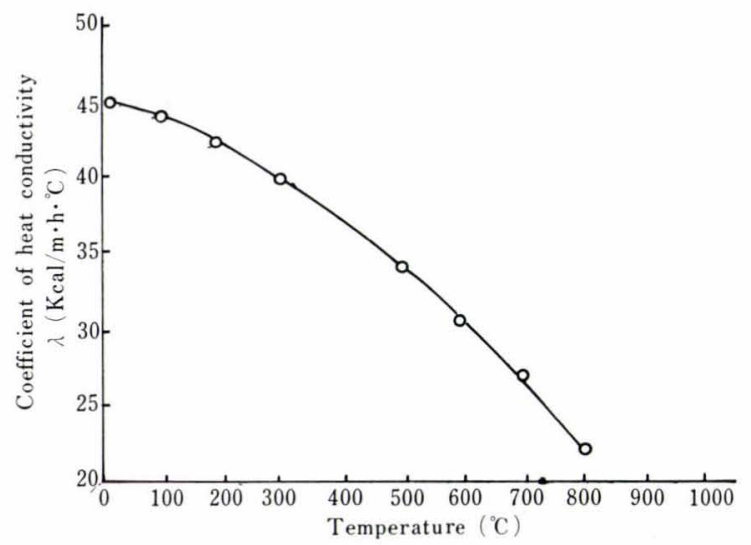

Fig. 1. Dependence-on-temperature of heat conductivity. Solid curve represents the relationship used in the computations.

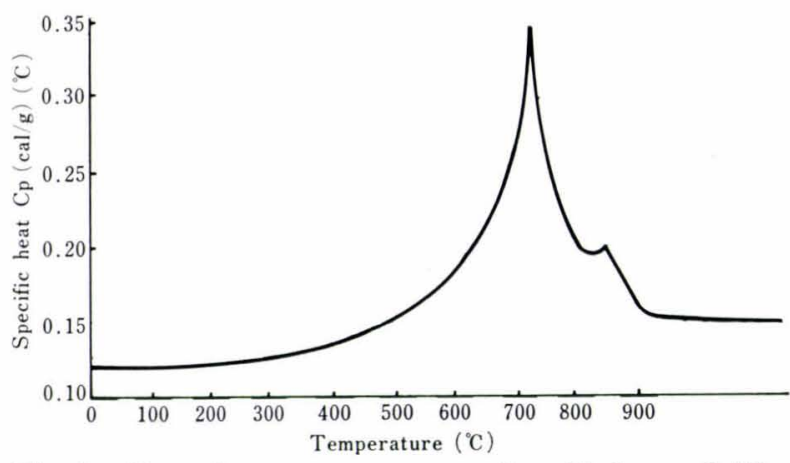

Fig. 2. Dependence-on-temperature of specific heat. Solid curve represents the relationship used in the computations.

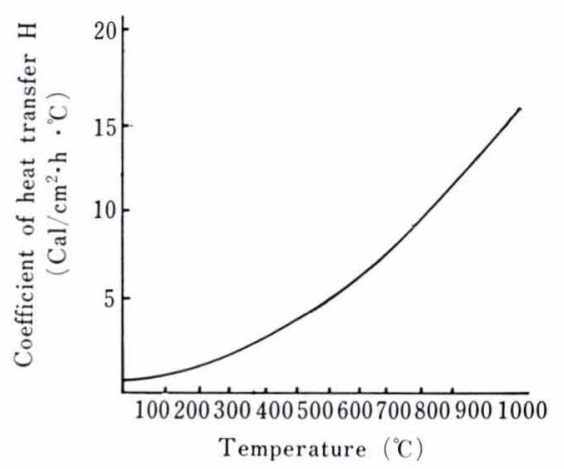

Fig. 3. Dependence-on-temperature of heat transfer. Solid curve represents the relationship used in the computations. is calculated from the 1st approximate temperature. From this calculated value, the second approximate temperature for time $T_{k+1}$ is obtained. Continuing the process, the physical coefficient is calculated from this second approximate temperature, and the third approximate temperature is obtained. These calculations are repeated several times, and the temperature at the point of convergence is adopted as the temperature at time $T_{k+1}$.

\section{Calculation of Thermal Stress}

A number of papers have been presented on methods for calculating thermal stress, but it is difficult to obtain a solution under complex conditions so that it is necessary to establish some assumptions for the solution. The following four assumptions were made:

(1) Only the stress in the longitudinal direction is considered for the $\mathrm{H}$-shapes.

(2) Plane sections remain plane.

(3) The material is a perfectly elastic-plastic at all temperatures.

(4) The mechanical material coefficients are known as a function of temperature.

If temperature should change from $T_{i, j, k}$ to $T_{i, j, k+2}$, elongation of $d \varepsilon^{T}(x, y, t+d t)$ will take place in the material due to the thermal expansion as shown in Eq. (6).

$$
\begin{aligned}
& d \varepsilon^{T}(x, y, t+d t) \\
& =\int_{T(x, y, t)}^{T(x, y, t+d t)} \alpha(x, y, T) d T \\
& \cong \frac{1}{2}[\alpha(x, y, T+\Delta \mathcal{T}) \cdot T(x, y, t+d t) \\
& -\alpha(x, y, \mathcal{T}) \cdot \mathcal{T}(x, y, t)]
\end{aligned}
$$

When both ends are not fixed, the interior distortion is the value of deviation from average elongation. Consequently, the interior distortion $d \varepsilon(x, y, t+d t)$ can be obtained from Eq. (7),

$$
\begin{aligned}
& d \varepsilon(x, y, t+d t) \\
& =-\frac{\iint d \varepsilon^{T}(x, y, t+\alpha t) d x d y}{\iint d x d y}+d \varepsilon^{T}(x, y, t+d t)
\end{aligned}
$$

On the other hand, when residual distortion of $\varepsilon^{E}(x, y, t)=[\sigma(x, y, t) / E(x, y, t)]$ is present before the temperature variation, the distortion after the variation at $(x, y)$ point can be obtained through Eq. (8),

$$
\varepsilon(x, y, t+d t)=\varepsilon^{E}(x, y, t)-d \varepsilon(x, y, t+d t)
$$

Therefore, thermal stress at point $(i, j)$ will be given in Eq. (9),

$$
\begin{aligned}
& E(x, y, t+d t) \cdot \varepsilon(x, y, t+d t) \\
& \text { if }|E(x, y, t+d t) \cdot \varepsilon(x, y, t+d t)| \\
& \leqq \sigma_{y}(x, y, t+d t) \\
& \sigma(x, y, t+d t)= \\
& \operatorname{SIGN}[\varepsilon(x, y, t+d t)] \cdot \sigma_{\mathrm{Y}}(x, y, t+d t) \\
& \text { if }|E(x, y, t+d t) \cdot \varepsilon(x, y, t+d t)| \\
& \geqq \sigma_{\mathrm{Y}}(x, y, t+d t)
\end{aligned}
$$




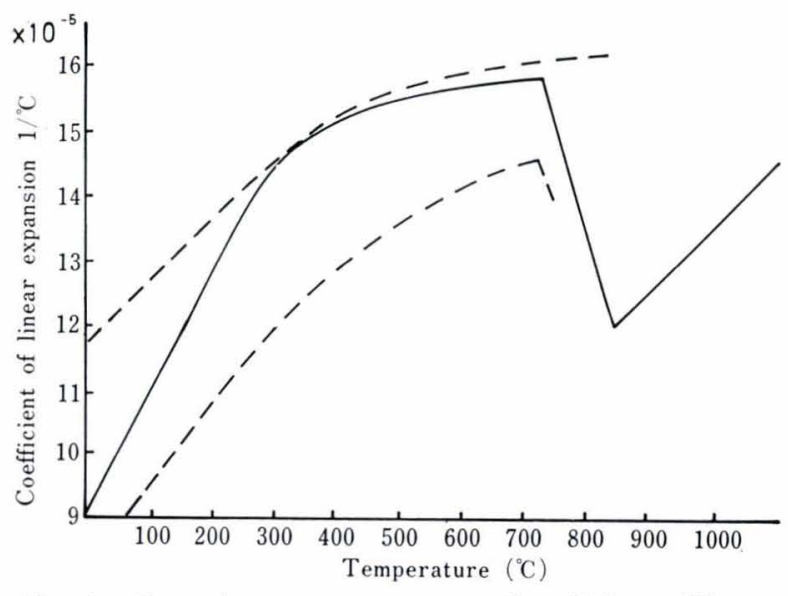

Fig. 4. Dependence-on-temperature of coefficient of linear expansion. Upper and lower bounds for test data of steel found in literatures survey are indicated with dashed curves in the diagram. Solid curve represents the relationship used in the computations.

However, equilibrium of forces cannot be satisfied by the stresses obtained through Eq. (9). For this reason, the average stress $R$ is computed through integration of the stresses obtained through Eq. (9),

$$
R=\iint \sigma(x, y, t+\alpha t) d x d y / \iint d x d y
$$

and $\varepsilon(x, y, t+d t)$ was corrected until a value below $1 / 100\left(\mathrm{~kg} / \mathrm{mm}^{2}\right)$ was obtained for $R$.

$$
\varepsilon(x, y, t+d t)=\varepsilon(x, y, t+d t)+R / 2 \cdot E(x, y, t+d t) \ldots
$$

These calculations were repeated after substituting Eq. (11) in Eq. (8).

\section{Mechanical Physical Constant}

The coefficient of linear expansion $\alpha(x, y, t)$, yield stress $\sigma_{Y}(x, y, t)$ and elastic constant $E(x, y, t)$ used in Eqs. (6) to (9) are all dependent on temperature. In making the calculations, the curves given in Figs. 4 to $6^{9)}$ were used. The procedures for calculations of temperature have been given in the foregoing paragraphs. Figure 7 shows a flow diagram for the computation of thermal stresses.

\section{Results of Calculations}

CDC 3600 and CDC 6600 were employed in the computation. For time interval, $1 \mathrm{hr}$ was divided into 130 intervals. At the initial stages, time interval was short because temperature variations were considerable. Later the interval was increased linearly with time increament. One-fourth of the cross section of $\mathrm{H}$-shapes was divided into 185 meshes.

\section{Cooling from a Uniform Temperature of $1000^{\circ} \mathrm{C}$ \\ 1. Comparison of Calculated Results with Measured Values}

In the preceding paragraphs, calculation methods for estimating residual stresses in $\mathrm{H}$-shapes have been discussed. In order to study the validity of the methods, a H-shaped steel $(6 \mathrm{~m})$ of $912 \times 302 \times 18 / 34$ was

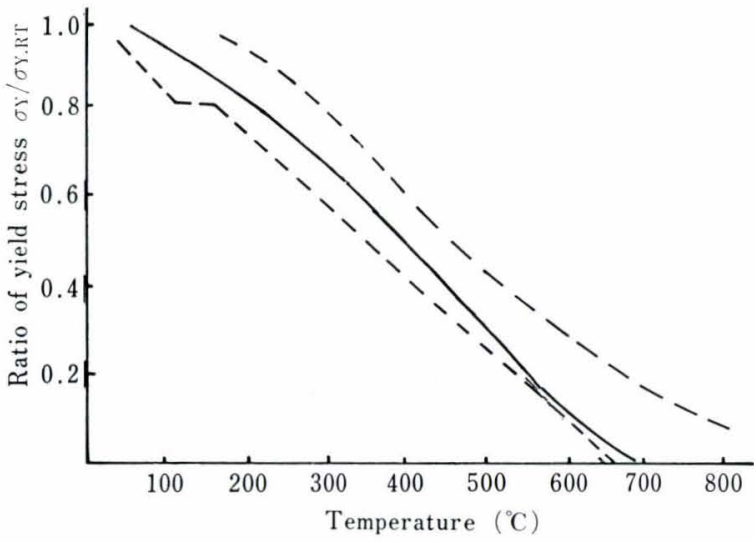

Fig. 5. Dependence-on-temperature of yield stress. Upper and lower bounds for test data of steel found in literatures survey are indicated with dashed curves in the diagram. Solid curve represents the relationship used in the computations.

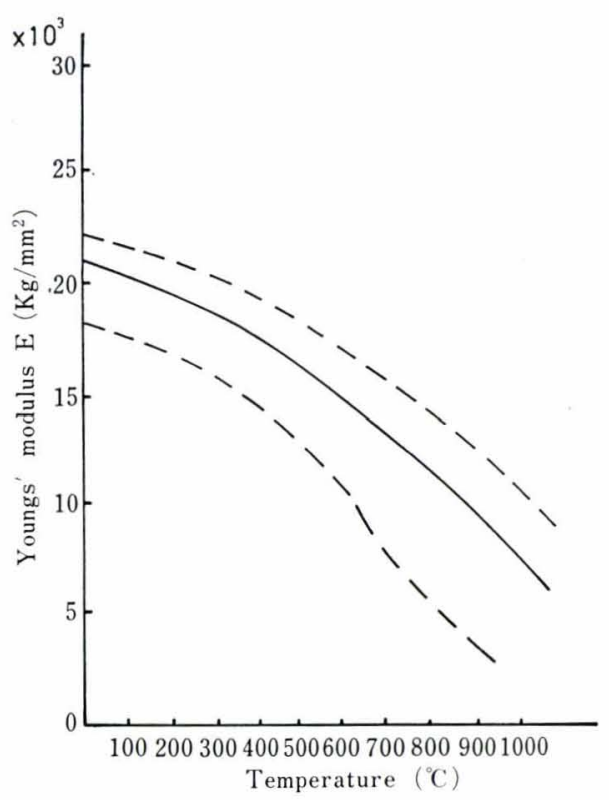

Fig. 6. Dependence-on-temperature of Young's modulus. Upper and lower bounds for test data of steel found in literatures survey are indicated with dashed curves in the diagram. Solid curve represents the relationship used in the computations.

heated to a uniform temperature of $1000^{\circ} \mathrm{C}$ in a large furnace (holding time: $20 \mathrm{~min}$ ). It was then cooled on a cooling bed and the residual stress distribution and temperature variations were measured for comparison with calculated values. Rand's pyrometer was used in the measurements. The temperature variations from $1000^{\circ} \mathrm{C}$ to room temperature are shown in Fig. 8. The solid line $T_{1}$ represents the calculated variations of temperature on the outer surface of the flange while the open circles represent measured values. The solid line $T_{3}$ gives the calculated temperature variations at the central surface of the web, while the " $x$ " marks indicate measured values. As the Rand pyrometer was used, temperatures below $450^{\circ} \mathrm{C}$ could not be measured.

However, the measured values down to $450^{\circ} \mathrm{C}$ ap- 


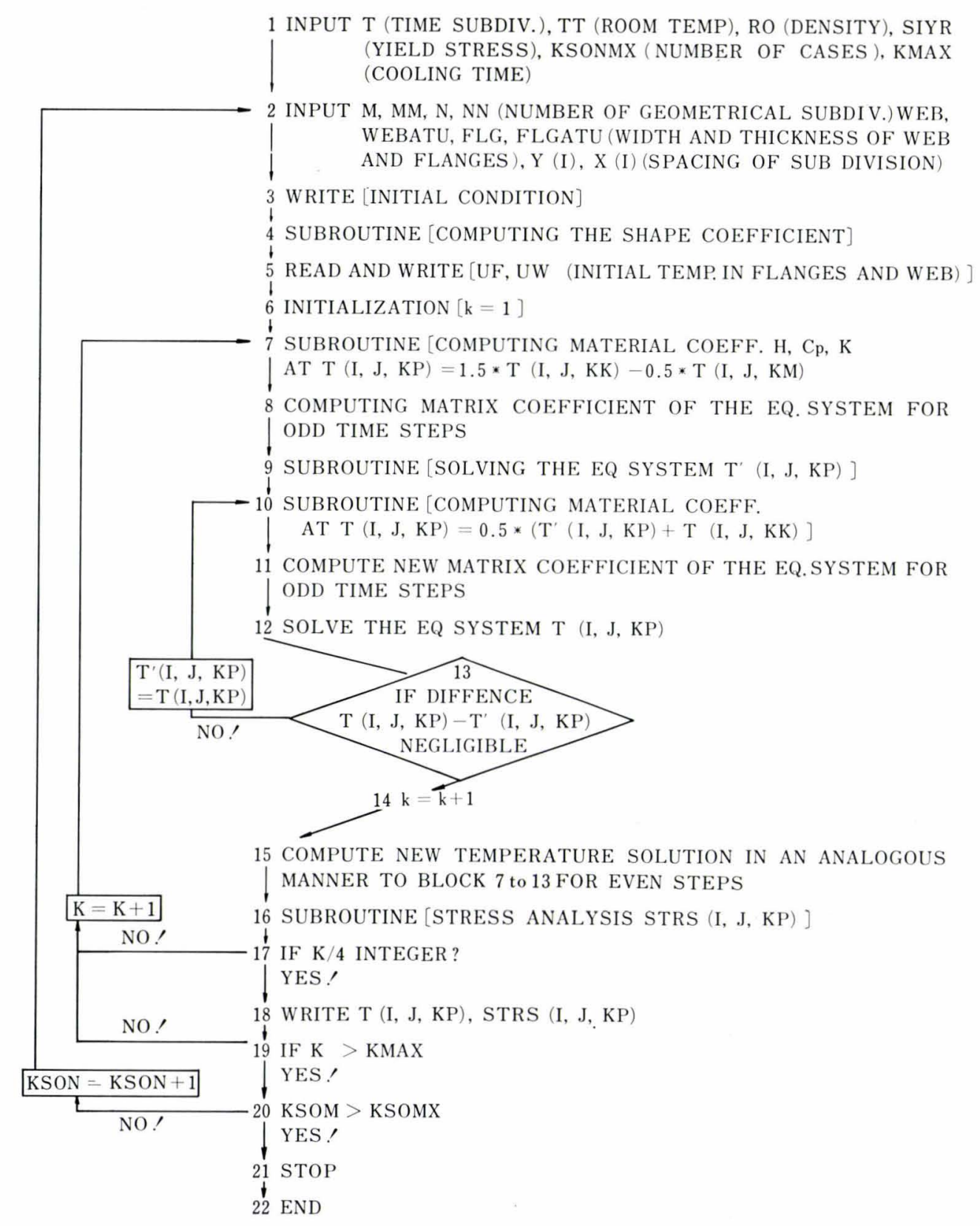

Fig. 7. Short flow diagram of computer program for temperature and stress analysis. (IAD method)

proximates the calculated values, which proves the validity of the method adopted. The web which is thinner than flanges cool much faster than the flange. The difference of temperature $T_{1}$ at the center of the flange and $T_{3}$ at the center of the web was calculated as the parameter to demonstrate the nonuniformity of the temperature generated in the member. Figure 9 shows the variation of temperature differences. As can be seen from the figure, the difference in the $\left(T_{1}-T_{3}\right)$ value increases very rapidly at first, reaches the maximum and then starts to decrease, indicating that the material transformation has started in the web. The curves start to increase again when the temperature of flanges reach the transformation point. After arriving again at the maximum value, the flanges cool to room temperature. Complex variations in $\left(T_{1}-T_{3}\right)$ are caused by the effect of the material transformation. The calculated value of the residual stresses developed in cooling from $1000^{\circ} \mathrm{C}$ was compared with the measured value using Contact Gage Method. (This method is explained in a separate paper on suppression and control of residual stresses in rolled H-shaped steel. ${ }^{4}$ ) The measured value (dotted line) and the calculated value (solid line) are shown together in Fig. 10. Both show similar distributions, indicating the residual stresses being about $10 \mathrm{~kg} / \mathrm{mm}^{2}$ of tension at the flange center, and about $-20 \mathrm{~kg} / \mathrm{mm}^{2}$ of compression at the web center. As is evident from the diagram, the measured value is greater by a few kilograms per square millimeter for the flange, and the distribution in the web differs to a certain extent between the two values, but, the absolute values at the center are approximately identical, and it is therefore thought that the residual stresses generated in rolled $\mathrm{H}$-shapes can be estimated through these calculations with a sufficient accuracy. 
Fig. 8.

Changes of temperature during natural cooling of $912 \times 302 \times 18 / 34$ wide flange beam from the initial uniform temperature $1000^{\circ} \mathrm{C}$. $T_{1}, T_{2}$ and $T_{3}$ are temperatures at the center of flange, at the end of flange and at the center of web, respectively. All the lines are theoretical.

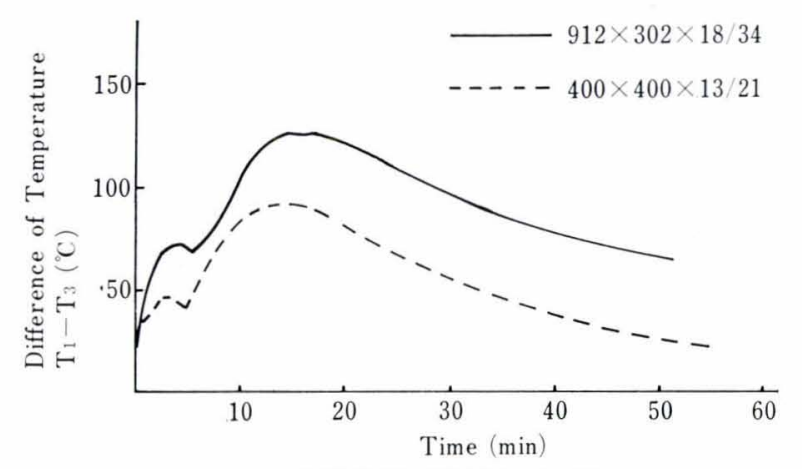

INITIAL TEMP. $1000^{\circ} \mathrm{C}$

Fig. 9. Variation of temperature difference $\left(T_{1}-T_{3}\right)$ during natural cooling of a wide flange beam from uniform temperature $1000^{\circ} \mathrm{C}$.

\section{Scale Effect on Residual Stresses}

In the preceding section, the validity of the calculating method for estimating the residual stresses were ascertained. In this chapter, the scale effect of residual stresses are examined through calculations. The conditions for the calculations embrace the natural cooling of various sizes of $\mathrm{H}$-shapes from a uniform temperature of $1000^{\circ} \mathrm{C}$. The residual stress value generated at the web center during this process, and the maximum values of the temperature difference $\left(T_{1}-T_{3}\right)$ generated during the cooling process as shown in Table 1. As shown in the Table, when the size is approximately identical, there is a tendency of increasing residual stresses with increasing $\left(T_{1}-T_{3}\right)$, giving rise to the thought that the maximum value of $\left(T_{1}-T_{3}\right)$ is an important factor in determining the value of the residual stresses. Also,

(1) In $\mathrm{H}$-shapes with identical $\mathrm{t}_{1} / \mathrm{t}_{2}$ (web thickness/flange thickness), greater residual stresses are generated for a larger size of shapes.

(2) In $\mathrm{H}$-shapes with identical flange width and web height, the smaller the $t_{1} / t_{2}$, the greater the residual stresses.

(3) In jumbo H-sizes where flange thickness and web thickness are especially great, the residual stress values are small as shown in Fig. 11.

However, this is the average value within the cross section, and actually, is due to the fact that there is
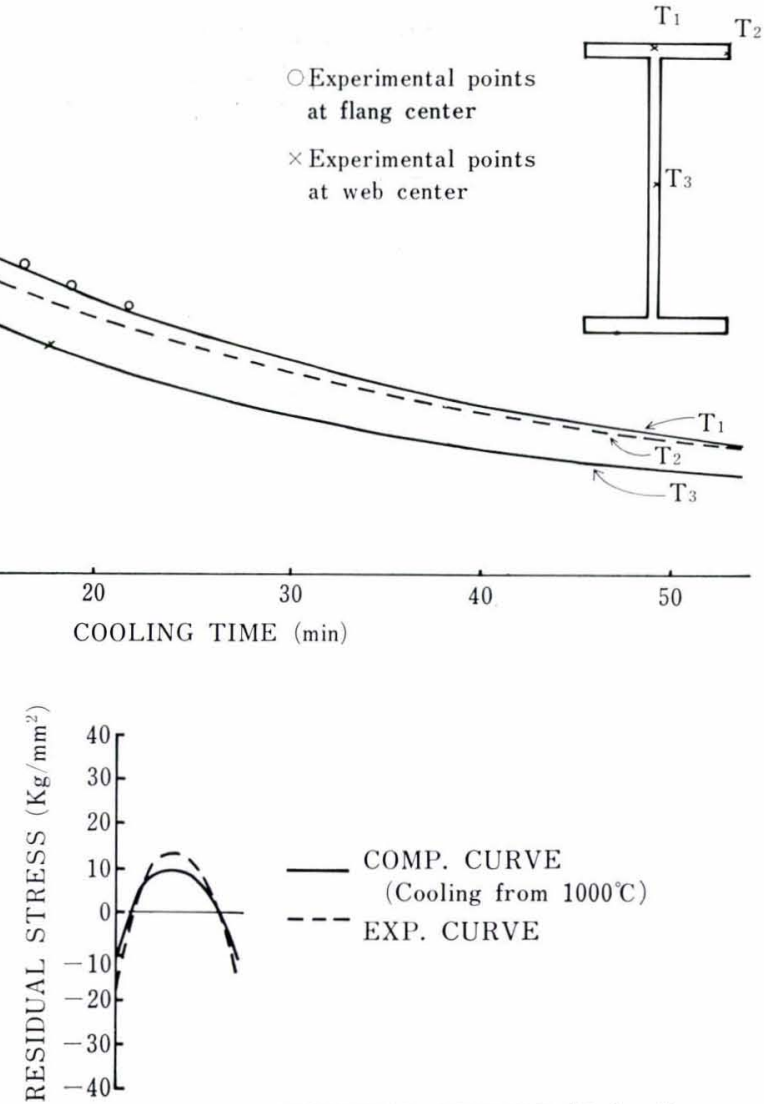

RESIDUAL STRESS $\left(\mathrm{Kg} / \mathrm{mm}^{2}\right)$
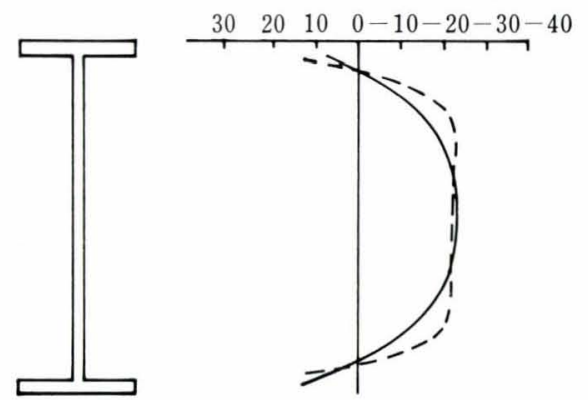

Fig. 10. Residual stress distribution in a $912 \times 302 \times 18 / 34$ wide flange beam.

Table 1. Residual stress and maximum temperature differences after cooling from a $1000^{\circ} \mathrm{C}$ uniform temperature.

\begin{tabular}{l|ccc}
\hline \multicolumn{1}{c|}{$\begin{array}{c}\text { Specimen size } \\
(\mathrm{mm})\end{array}$} & $\mathrm{t}_{1} / \mathrm{t}_{2}$ & $\begin{array}{c}\text { Residual } \\
\text { stress in the } \\
\text { web center } \\
\left(\mathrm{kg} / \mathrm{mm}^{2}\right)\end{array}$ & $\begin{array}{c}\text { Maximum } \\
\text { temperature } \\
\text { difference } \\
\left(T_{1}-T_{3}\right)\left({ }^{\circ} \mathrm{C}\right)\end{array}$ \\
\hline $912 \times 302 \times 18 / 34$ & 0.528 & -23.0 & 145 \\
$400 \times 400 \times 13 / 21$ & 0.620 & -18.0 & 95 \\
$200 \times 200 \times 6.5 / 10.5$ & 0.620 & -13.0 & 63 \\
$200 \times 200 \times 8 / 15$ & 0.533 & -16.1 & 78 \\
$498 \times 432 \times 45 / 70$ & 0.644 & -9.6 & 56 \\
\hline
\end{tabular}

a great difference in the value of the residual stresses across the section. In Fig. 12 is shown the two dimensional residual stress distribution within the jumbo H. As shown in the diagram, there is a difference of more than $15 \mathrm{~kg} / \mathrm{mm}^{2}$ between the outer surface of the flange and the middle of it. 


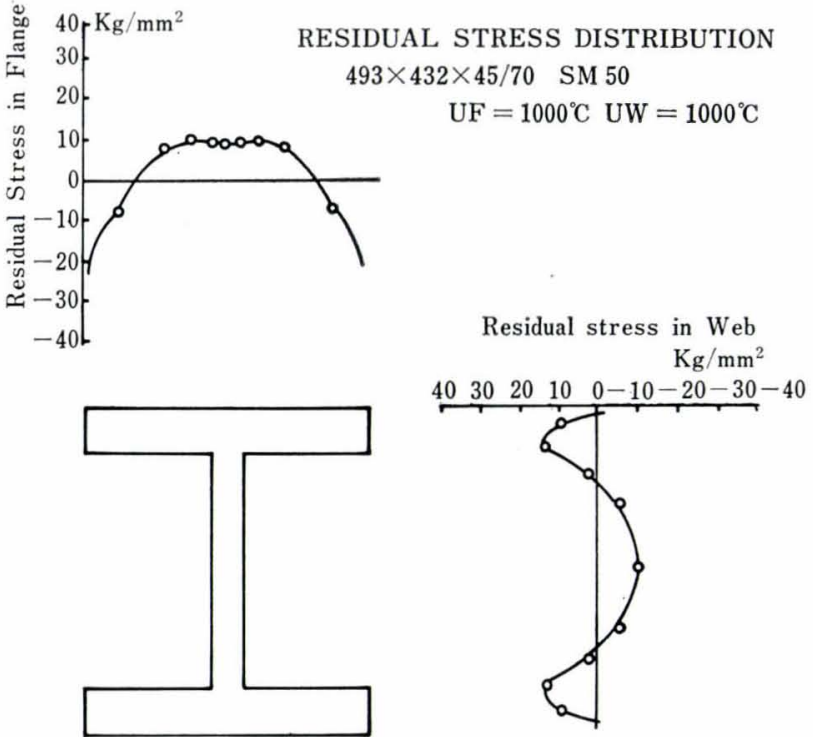

Fig. 11. Calculated residual stress distribution in the $498 \times$ $432 \times 45 / 70$ Jumbo H-beam cooled from uniform temperature $1000^{\circ} \mathrm{C}$; the values shown in this figure are the average across the section.

\section{When There Is an Initial Temperature Difference be- tween the Web and Flange}

In the preceding section, the conditions under which $\mathrm{H}$-shapes were cooled from a uniform temperature of $1000^{\circ} \mathrm{C}$ were discussed. However, hot-rolled $\mathrm{H}$-shapes are not uniformly cooled during the rolling process due to the different cooling conditions between web and flanges. Cooling water of rolls, for example, remains on the web during rolling. As the result of these difference, at the time of completion of the rolling operation, differences in the temperature have already been developed between the web and flange. In order to observe the effects of this initial temperature difference, the following three cases were computed for $H$-shapes of $912 \times 302 \times 18 / 34$, assuming that the entire flange and the entire web are initially at constant temperatures of $\mathrm{UF}$ and $\mathrm{UW}$, respectively.

(1) $\mathrm{UF}=870^{\circ} \mathrm{C}, \mathrm{UW}=770^{\circ} \mathrm{C}$

(2) $\mathrm{UF}=870^{\circ} \mathrm{C}, \mathrm{UW}=720^{\circ} \mathrm{C}$

(3) $\mathrm{UF}=820^{\circ} \mathrm{C}, \mathrm{UW}=670^{\circ} \mathrm{C}$

In each case, as shown in Fig. 13, the temperature variations during the cooling process are similar. However, a greater temperature difference, $\left(T_{1}-T_{3}\right)$, appears in the specimen with a greater initial temperature difference. The residual stress distributions are given in Fig. 14. It can be seen that the smaller residual stresses are developed in the specimen with a smaller initial temperature difference.

Also, in order to observe the effects of the initial height of temperature on residual stresses, the initial temperature difference was assumed to be constant of $200^{\circ} \mathrm{C}$, and calculations were made on the following three cases:
(1) $\mathrm{UF}=930^{\circ} \mathrm{C}, \mathrm{UW}=730^{\circ} \mathrm{C}$
(2) $\mathrm{UF}=870^{\circ} \mathrm{C}, \mathrm{UW}=670^{\circ} \mathrm{C}$
(3) $\mathrm{UF}=820^{\circ} \mathrm{C}, \mathrm{UW}=620^{\circ} \mathrm{C}$

Here, from the computed results, the generated maximum temperature differences $\left(T_{1}-T_{3}\right)$ were almost

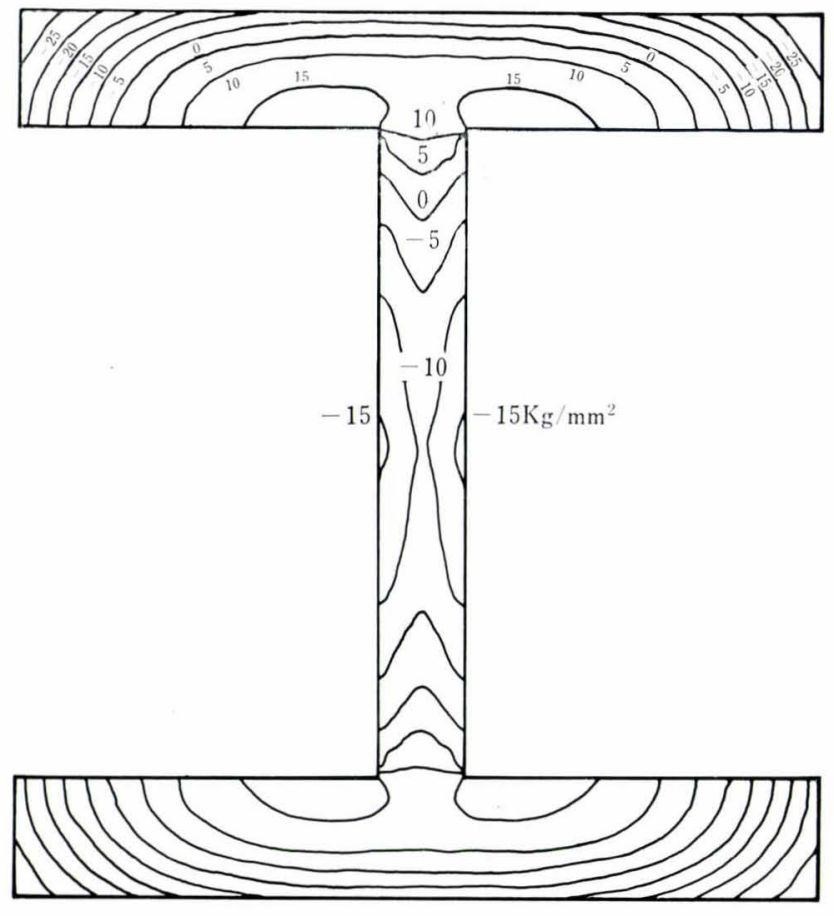

Fig. 12. Computed two-dimensional residual stress distribution in Jumbo $\mathrm{H}(498 \times 423 \times 45 / 70)$ cooled from uniform temperature $1000^{\circ} \mathrm{C}$. (natural cooling)

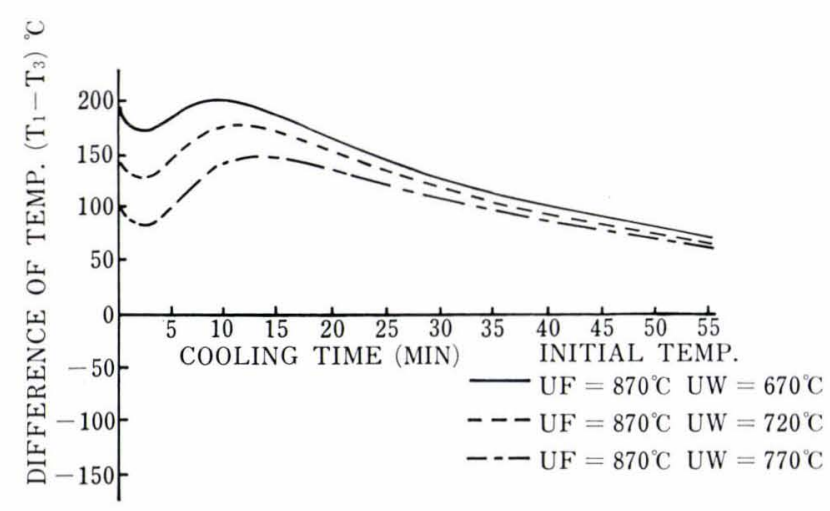

Fig. 13. Computed temperature difference $\left(T_{1}-T_{3}\right)$ of $912 \times 302 \times 18 / 34$ wide flange beams cooled from different temperature.

the same, and the residual stresses in all cases are almost the same. It is therefore concluded that the differences in the initial temperatures within the temperature range mentioned above, have no significant effects on residual stress.

\section{Conclusion}

The mechanism of how residual stresses develop thermally in hot-rolled H-shapes, the calculation method for the estimation of residual stresses and the results of the computations were discussed in the paper. The results are summarized as follows.

(1) The residual stresses of rolled $\mathrm{H}$-shapes can be estimated through a computation of the cooling process by using a simplified two dimensional model.

(2) The main cause of the formation of residual stresses is the nonuniformity of temperature generated 


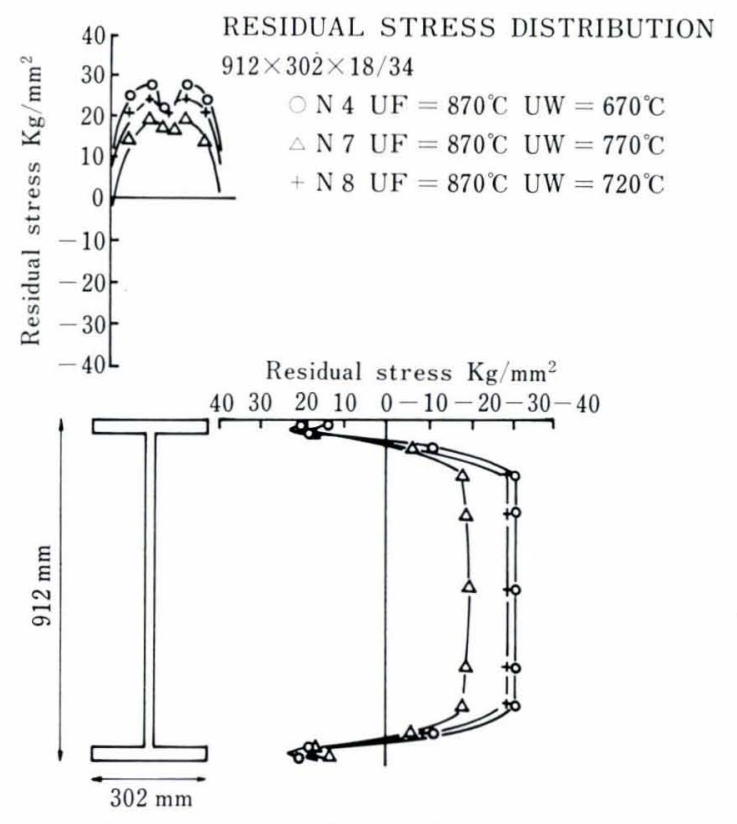

Fig. 14. Computed residual stress distributions cooled from different temperatures.

during the cooling period. And the main factor which especially determines the value of residual stresses is the maximum value of $\left(T_{1}-T_{3}\right)$ which represents the difference of temperature at the center of the flange and at the center of web.

(3) The spapes of $\mathrm{H}$ has large effects on residual stresses, great residual stresses being generated in large sized $\mathrm{H}$-shapes in direct proportion to the height of the web provided that $t_{1} / t_{2}$ is identical. Also, if the width of the flange and the height of the web are the same, the smaller the $t_{1} / t_{2}$, the greater the residual stresses generated.

(4) If there is a difference in the temperatures of the web and flange at the beginning of the cooling period, greater initial temperature differences develop larger residual stresses. However, if the initial temperature difference is the same and the absolute value is between $900^{\circ} \sim 700^{\circ} \mathrm{C}$ at the flange, there will be no difference in the magnitude of residual stresses.

We may conclude from the discussion above that the essential mechanism of the generation of residual stresses in hot-rolled $\mathrm{H}$-shapes have been clarified, but further studies should be conducted regarding the methods for controlling and removing the residual stresses, and also the adverse effects of the residual stresses on performances.

\section{Nomenclature}

$x, y, z:$ Cartesian coordinates $(\mathrm{cm})$

$\Delta x, \Delta y$ : Length of sub-division in the $x, y$ direction (cm)

$n$ : Coordinate vertical to surface area $(\mathrm{cm})$

T: Temperature $\left({ }^{\circ} \mathrm{C}\right)$

$T_{\text {atm }}$ : Ambient temperature $\left({ }^{\circ} \mathrm{C}\right)$

$\lambda$ : Thermal conductivity $\left(\mathrm{kcal} / \mathrm{m} \cdot \mathrm{hr} \cdot{ }^{\circ} \mathrm{C}\right.$ )

$H$ : Coefficient of heat transfer $\left(\mathrm{kcal} / \mathrm{m}^{2} \cdot \mathrm{hr} \cdot{ }^{\circ} \mathrm{C}\right.$ )

$Q$ : Calorific value $\left(\mathrm{kcal} / \mathrm{m}^{3} \cdot \mathrm{hr}\right)$

$C_{p}$ : Specific heat $\left(\mathrm{cal} / \mathrm{g}^{\circ} \mathrm{C}\right)$

$\alpha$ : Coefficient of linear expansion $\left({ }^{\circ} \mathrm{C}^{-1}\right)$

$\rho:$ Density $\left(\mathrm{g} / \mathrm{cm}^{3}\right)$

$E$ : Young's modulus $\left(\mathrm{kg} / \mathrm{mm}^{2}\right)$

$\nu$ : Poisson's ratio

$\varepsilon$ : Distortion

$\varepsilon^{T}$ : Thermal expansion

$\varepsilon^{E}:$ Elastic distortion

$d \varepsilon$ : Increment of distortion

$\sigma:$ Stress $\left(\mathrm{kg} / \mathrm{mm}^{2}\right)$

$\sigma_{\mathrm{Y}}:$ Yield stress

$\sigma_{\mathrm{YRT}}$ : Yield stress at room temperature $\left(\mathrm{kg} / \mathrm{mm}^{2}\right)$

$t$ : Time (sec)

$i, j:$ Mesh division points in the $X, Y$ directions

$k$ : Time division

Here, the suffixes $\left(T_{i, j, k}\right),\left(\alpha_{i, j, k}\right),\left(E_{i, j, k}\right),\left(\sigma_{i, j, k}\right)$ and $\left(\varepsilon_{i, j, k}\right)$ indicate values at $(i, j)$ points of time $k$.

\section{REFERENCES}

1) T. Kusakabe and Y. Mihara: Plastic Working Symposium, The Japan Society for Technology of Plasticity, (1972), $61 \sim 64$.

2) N. G. Bochkov, M. V. Gutnik, and Ya. S. Gallai: Stal', 11 (1972) 1016.

3) J. B. Lean: Proc. ICSTIS, II, Suppl. Trans. ISIJ, 11 (1971), 733.

4) T. Kusakabe and Y. Mihara: to be published in Trans. ISIJ.

5) Y. Kohdo: Electrothermics, Yoken-do, Tokyo, (1964), 30.

6) Y. Kohdo: Electrothermics, Yoken-do, Tokyo, (1964), 43.

7) G. D. Smith: Numerical Solution of Partial Differential Equations, Oxford University Press, (1965), Trans. by Y. Fujikawa, Science Company, Tokyo, (1971), 155.

8) Data on the Physical Constants of Metallic Material, Data Book from the Committee on High Temperature Structural Strength, The Society of Materials Science, Japan, (1970).

9) Physical Constants of Some Commercial Steels at Elevated Temperatures, Butterworths Scientific Publication, London, (1953). 